\title{
Impact of Local Economic Development on Livelihoods in Ba-Phalaborwa, South Africa
}

\author{
Seduma Matee Piet \\ University of Limpopo, Turfloop Graduate School of Leadership \\ Webster Street, Edupark, Fauna Park, PO Box 759, Polokwane 0787, Republic of South Africa \\ Oliver Mtapuri \\ University of Limpopo, Turfloop Graduate School of Leadership, Webster Street, Edupark, \\ Fauna Park, PO Box 759, Polokwane 0787, Republic of South Africa \\ Email address: simbaomtapuri@yahoo.com \\ Alternate email: oliver.mtapuri@ul.ac.za
}

\section{Doi:10.5901/mjss.2014.v5n14p18}

\begin{abstract}
Local Economic Development has been adopted by the South African government as one of the strategies to alleviate poverty and reduce unemployment. This article evaluates the impact of Local Economic Development on the livelihoods of communities in the Ba-Phalaborwa Local Municipality. The article contributes to the understanding of local economic development in the context of community projects which are regarded as LED projects. The article used both qualitative and quantitative research designs in which a questionnaire and interviews were used for data collection. The article argues that there is need to offer adequate infrastructure in order to enhance business development in a rural, sub-urban or urban environment and that local economic development is important in a municipal context in the reduction of poverty, unemployment and the creation of jobs. The major contribution of this article is a model of LED projects which empowers communities for self sufficiency; nurtures community cohesion and development; creates jobs, encourages community participation; generates incomes; fosters cooperation and partnerships; allows for the spread of technical support; promotes networks, local cultures and traditions; and the building of sustainable communities.
\end{abstract}

Keywords: Local economic development, poverty reduction and unemployment.

\section{Introduction}

Local Economic Development has been adopted by the Republic of South African Government as one of the strategies to impact on the livelihoods of communities in the alleviation of unemployment and poverty. The local government sphere of governments is expected to stimulate economic growth and ensure that local economic development initiatives achieve the set goals of the National Development Plan (2030 Vision). Essential powers have been devolved to local governments to lead Local Economic Development (LED), with the Constitution of the Republic of South Africa, (Act 108 of 1996) and the Local Municipal Systems Act, Act No.32 of 2000, affirming the importance of LED towards sustainable development.

This article highlights a context in which unemployment and poverty alleviation undergirded by job creation are key items on the South African Government's agenda to achieve economic growth and sustainable development. To that end, the South African government is channeling resources towards supporting small, micro and medium enterprises (SMMEs), to create sustainable livelihoods for both individuals and communities. The direct participation of local communities in the mainstream of their local economies is, therefore, crucial in reducing poverty and unemployment and creating jobs.

\section{Literature Review}

\subsection{Local Economic Development: an international perspective}

The World Bank recommends that poverty alleviation initiatives through LED should be integrated to provide poor 
communities with the necessary basic services such as water, electricity, education, health care, roads and sewerage. Active participation of the beneficiary communities in LED initiatives is necessary in endeavours to achieve meaningful economic growth. The World Bank (2003) further views LED as a process in which the public, business community and non-governmental sectors should partner and work collectively to create better conditions for economic growth and employment generation. Local Economic Development provides the opportunity to locals to work together in order to improve the quality of lives of all citizens (World Bank, 2005). For Phillip (2003), LED has been pursued through the establishment of co-operatives in five distinct traditions such as consumer co-operatives, worker co-operatives, the credit co-operatives, agricultural co-operatives and service co-operatives, whose beginnings have been associated with the Rochdale pioneers and proliferation in France, Germany, Denmark and other parts of Europe.

LED promotes the active participation of local communities in their own development rather than be the objects of development. Community-driven initiatives represent ways in which communities could conserve local customs and traditions while earning a living at the same time (Pretorius \& Blaauw, 2008). In that vein, the traditional view of LED, as a process of having developmental initiatives aligned to local development, has shifted towards promoting self sufficiency, regional, national, continent-wide development within a global context to shape local economies and support LED across the all spheres of governance. The European Union serves as a good example of how LED, with its components anchored in national and regional governments, supports local development processes (DPLG, 2006).

In the 1990s, Local Economic Development took an international shift by adopting economic growth driven strategies to promote development. Small scale and community based initiatives aimed at using local skills and the participation of the communities to ensure sustainability were preferred. LED initiatives were regarded as proactive actions by the people to create economic opportunities and improve their social conditions. Abrahams (2003) identified a number of LED initiatives to address particular social and economic challenges at the local level such as focusing on the mobilization of local resources, redistribution of resources, promotion of local creativity and innovation, investment in human capital, the provision of technical assistance and training for self-employment and business start-up and support for enterprise creation. Most western countries regarded LED as an important tool to deal with poverty (Simon, 2003) using community-based initiatives such as co-operatives as the anchor vehicles.

Nel and Rogerson (2005) posit a variety of responses in terms of how economic development is perceived from various localities, where some view economic development from a pro-poor or pro-growth focus, while others define it from a combination of the two. The distinction of the two is clearly depicted by the pro-growth sentiments that focus on creating conducive environments for investment while pro-poor's objective focus on poverty alleviation through job creation. There are great expectations on LED projects to deliver in terms of addressing social ills such as of poverty, inequality and unemployment. LED initiatives and implementation have gone through various stages and there is no common approach to implementation. From a global context, it is clear that there are various challenges embedded in the planning, funding and implementation of LED strategies and initiatives as a way of alleviating poverty, unemployment and creating massive jobs, at the same time providing relevant training and skills development to the beneficiaries.

LED from an international perspective is used by communities with a need for modernization to develop and adopt economic programs as vehicles for economic growth. As such, developmental local government needs to prioritize economic strategies which are able to design effective instruments which promote relevant objectives and use locally identified instruments including forging formal institutions as well as informal networks of collaboration among citizens and officials to realize and utilize new opportunities for trade and profitable production (Bagchi, 2000).

\subsection{LED: the South African perspective}

Nel and Humphrys (1999) state that LED is currently receiving much attention in South Africa especially after 1994 when South Africa was faced with a lot of socio-economic and developmental challenges, extreme inequalities in income, assets and basic social services. Reitzes (2004) agrees that most of the South African families and households live in poverty, and are illiterate, poor, survivalist and live in unhygienic environments with high unemployment levels.

Malefane (2009) attests that even though LED is perceived as a municipal intervention, it is not being efficiently implemented in most South African municipalities. The skewed apartheid spatial development planning deliberately alienated the majority from the central means of economic activity, by uprooting most of the African communities from their original economic means of subsistence and family systems. The current widening of the rich-poor economic gap has been acknowledged as a challenge by the South African government. Davids (2005) argues that in order to address the injustices of past, development efforts in South Africa must adopt a people-centred approach described by Theron (2005) as shifting of interventions towards the public and enhance the public's skills and capacity by encouraging participation in development processes. 
Malefane and Mashakoe (2008) argue that despite the provisions laid down in the Local Government (Municipal Systems Act of 2000), the South African municipalities continue to operate without having authority and assessments of progress regarding LED implementation. Nel and Rogerson (2005) argue that the ability to impact meaningfully on poverty and encourage economic growth is dependent on resources allocated to LED. Currently there are disparities between various municipalities regarding the resources allocated to LED. Kroukamp (2006) states that unrealistic expectations by the public and the need for transformation has led to a series of financial crises and inability by municipalities to fund services. Human, Marais and Botes (2008) argue that there is still confusion between LED and poverty alleviation. Officials in government have different opinions regarding what LED actually entails. Some attribute LED to community poverty alleviation projects, while others believe that the focus of LED falls mainly on the major economic thrusts that should result in poverty alleviation efforts.

Rogerson (2003) argues that LED is more entrenched in policy than in practice. The South Africa state has adopted pro-poor policies, but not in practice because LED policies in the South African context are at odds with the prevailing neo-liberal macro-economic strategy of the country, creating tension as to whether LED should be about propoor or pro-growth interventions or both. Phago (2004) states that municipal LED in South Africa has not been fruitful or effectively functional.

Meyer-Stamer (2002) is very critical of LED in South Africa by positing that it is not clear whether or municipalities are supposed to be the drivers of the LED process, facilitator or active observer of processes as driven by the local business sector. Nel and Rogerson (2005) state that despite the fact that some centres have been actively engaged in the pursuit of LED for nearly a decade, very few are able to provide a realistic appraisal of their achievements and impact to date. LED as contextualised from the South African perspective stipulates that it has to be pro-poor in orientation, enjoying the national state endorsement of local-level action and requires a combination of private and public partnerships to address specific socio-economic problems as a local government mandate (Rogerson, 2003 and Nel, 2001). This reflects LED as a highly contested area.

Steytler, Titus, Carrim \& Mkhalipi (2002) see municipalities as an indispensable part of South Africa's system of government since they have to ensure that Government policies and programmes are coordinated and aligned to those of national and provincial spheres of government. Therefore, Local Economic Development problems in South Africa should be carefully analysed in relation to the multiplicity of challenges and experiences from the past as well as the present.

\section{Methodology}

Both qualitative and quantitative data were collected using semi-structured questionnaires focusing on participants involved in identified LED projects within Ba-Phalaborwa. The research process was based on the assumption that LED initiatives were undertaken by municipalities and other interested private parties to alleviate poverty and create jobs. The data analysed was derived from individual and focus group interviews which provided a detailed description and explanations of the real situation on the ground in relation to the impact of LED initiatives on communities.

Using a total 11 sampled community projects out of list of 100 community projects, a total of 162 respondents were interviewed using purposive sampling in order to select information rich respondents (Bernard, 2000). The participants interviewed have adequate experience and knowledge of working in LED projects. The projects produce a variety of products such as arts and crafts, poultry, eggs, sewing and roof tiles for the different targeted markets. Interviews were conducted in most of the cases because of the low literacy levels of the respondents. Semi-structured questions allowed flexibility and gave room to make follow-ups on grey areas. Field notes were used to record data in addition to the interview schedule (Schurink, 2005a: 11 and De Vos et al, 2005). The research was conducted over a period of two months due to the wide geographic spread and location of the projects.

\section{Findings}

The impact of LED on the livelihood of the respondents varies from project to project, based on the levels of income and benefits derived from the projects. Most of the projects operate in areas without proper business infrastructure such as banks, telecommunication, good roads and proper electricity supply, thus limiting their potential to maximise their productivity. The environmental context in which the majority of the projects are operating is rural, with the rate of poverty, illiteracy and unemployment being very high. A total of 171 people are employed in the identified projects.

Fifty-four per cent of the community members interviewed produce similar products while projects in manufacturing, agriculture and other clusters form $18 \%$ of the projects. This implies that projects producing similar products face intense competition amongst themselves making profitability difficult. 
Almost all of the products produced by the projects have readily available local markets in the local communities, and for makeshift events such as pension pay-points, exhibitions and schools. However, given the widespread poverty in the areas, the viability of the projects is threatened. Some projects such as Hlanganani (for curios near the Kruger National Park), Bollanoto (for tourism information and exhibitions) and Chivirikani (for arts and crafts) have established permanent selling points to reach out to their clients.

Ninety percent of the respondents confirmed that they joined the community projects to fight poverty and unemployment, $72 \%$ wanted to create jobs for their immediate communities, $27 \%$ wanted to gain skills and $9 \%$ wanted to seize economic opportunities and develop their communities. Respondents claimed that they have gained some experience and skills by participating in community projects which exposed them to holding strategic positions in such fora as either chairperson, treasurer, secretary, leadership, management, organising, bookkeeping and managing the project. These functions reflect the empowerment of community members.

One of the prime benefits of participation in the LED projects was the income derived there from. A total of 164 households, with close to 625 household members depending on the proceeds and rewards from the community projects and were receiving incomes generated from these projects, albeit minimal. In focus group discussions, most of the respondents confirmed that their income levels improved since joining the community projects as such their standards of living improved immensely with the income derived from the projects in supporting their families. With the unemployment rate standing at $43 \%$ (IDP, 2010), a high proportion of people without income estimated to be around $11 \%$ in 2007 , the community projects have made a difference in the livelihoods of people by providing them with some form of employment. Projects such as Hlanganani with 175 and Titirheleni with 90 had the highest number of dependants of the sampled projects.

Revenues from projects were deployed variously. Sixty-four percent of the received funds were in the form of a grant. Seventy-two percent of the projects used the funds received for buying stock; with $64 \%$ of those projects using the funds received for construction. Thirty-six percent of the projects claimed they received support in the form of technical assistance and $27 \%$ of the projects, with $18 \%$ further using the funds for training and buying of equipment for use in the projects. Only $9 \%$ of the funds were used to pay for water and electricity.

A fairly high attrition rate can be observed in some of the projects and an equally high retention rate can be observed in others. Fifty-nine percent of the members who started with the community LED projects have since left leaving the remaining members to run the projects. For example, Chivirikani project once had over 200 members but lost $90 \%$ of its members due to lack of sustained income coupled with disputes and disillusionment leading to mass resignations.

Only four of the projects had a positive net gain of new members since their inception: Hluvukani with 20\%, Mosa Multi Purpose 42\%, Titirheleni Vamanana $42 \%$ and Hlanganani Curio Shop 35\%. Hi-Kurhile had a constant number of members remaining with the project. Thus this presents a mixed picture of the attrition and retentions in projects. On analysis, of the five (5) projects relatively doing well, consistent income and cash-flows have allowed them to retain members who draw stipends on a monthly basis. Hlanganani has a large pool of clients visiting the Kruger National Park which in turn has a positive effect on their revenues.

A majority of projects which experienced declines in people employed cite not having sustained income and family pressures as factors explaining the declines. Six of the identified projects had decreases in membership ranging from $13 \%$ to $90 \%$.

Lack of income was the main reason for losing members. The main reasons for low income levels could be linked to products not appealing to the clientele; members expecting to be paid stipends even when project sales were low; using money set aside for buying stock and re-investments for other purposes. Because most of the respondents come from poor backgrounds and depend on the projects for survival further imposing a heavy burden on the project with adverse impacts on the survival of the businesses. It could be observed the respondents regarded any financial support received from sponsors as part of the monies earmarked to cover for stipends or salaries leading to chronic cycles of expecting more funding to be injected into the projects on a continuous basis, affirming what literature says that projects continue to expect funding even beyond the period of funding.

Forty-five percent of the projects interviewed earn a monthly income between R1,000-R12, 000, 18\% have monthly income between R13,000 and R24,000, and 13\% earning just above R37,000 per month. Forty-five percent of the projects have monthly expenditures between R900-R12,000, 27\% have expenditures between R13,000-R24,000, and 9\% have expenses in excess of R25,000- R37,000 respectively. Eighty-one percent of the projects interviewed use word of mouth to advertise products into market, with $45 \%$ attending exhibitions and $9 \%$ using special events, radio, advertising boards, business cards, brochures, school visits, and presentations to market their products. The scenario which this picture paints is survivalist. 


\subsection{Financial sustainability}

On one hand, $45 \%$ of the projects has relatively positive cash-flows with the same percentage of project expenditures incurred to cover salaries, electricity, raw materials, telephone bills and marketing against the gross incomes derived. On the other hand, some projects, such as Chivirikani, are running at a loss because of the income derived from sales is way below monthly expenditures. This makes the business initiative not financially sustainable. Hlanganani receives no financial support from any of the public and private sector departments, businesses or institutions. The project is run based purely on business principles. The project has a gross income of around R50, 000 per month and overhead expenses around R16,000. This leaves the project with almost $68 \%$ of revenue generated to be saved or re-invested into the project. However, almost all members in the projects stated that they still expected financial support.

Eighty-one percent of the interviewed project members indicated that project members were trained or had gained some experience in project management. However, considering the fact that most of the respondents interviewed have very limited educational levels, it is clear that only basic training in project management was imparted with regard to what each respondent is expected to do on a daily basis. Members from two projects (19\%) of the projects members interviewed, (Hi-Kurhile and Bollanoto) did not receive any training in project management. The implication is that the majority of the project members interviewed could gain a lot if intensive project management training was offered which the respondents deemed to be a very crucial skill.

\subsection{Demand for products}

Sixty-three per cent of the sampled projects found it hard to maximise the demand for their products. Only Hlanganani, Hi-Kurhile, Titirheleni Vamanana and Hluvukani Roof Tiles have realised consistent demand for the products they produce. For Hlanganani, the market clientele is at the gate of the Phalaborwa Kruger National Park and tourists find it easy to access the products produced in the curio-shop.

Among the challenges which the projects are facing, forty-five percent of the projects cited transport challenges as negatively impacting on the operations of their enterprises; while $27 \%$ of the projects find it very difficult to market their products; $18 \%$ registered theft and low incomes as major problems; and $9 \%$ of the projects state that lack of skills, sponsors, manufacturing infrastructure including resignations, water, equipment, expensive land sites and municipal support as their major challenges. These tallies well with what researchers have alluded as challenges facing community projects to attain sustainable levels.

A majority of the project respondents received some form of training related to the running of the projects. However, the likely impact of the training received is hampered by the low educational levels of the respondents given that a majority of projects are run by elderly people, with youth not interested in joining community projects. Mponeng and Hlanganani did not receive any form of training on how to run a project. The respondents stated that they would like to receive training and mentoring on project management, skills development, financial management, marketing, cost and pricing, bookkeeping and business management.

\section{Discussion}

Most of the projects are run as charity organisations and not as businesses. Members still expect to be financially supported through grants without them re-investing the little resources or profits made into the businesses. Such a mentality must change if the projects are to succeed in creating jobs, empowering members, generating income and so forth. This problem has been compounded by the fact that the environmental context in which the majority of the projects are operating is predominantly rural with high levels of poverty, illiteracy, and unemployment. These are also the same reasons why these projects were initiated, namely, to alleviate poverty, unemployment and to create jobs. Other secondary reasons for these projects include skills development, networking, cultural promotion, and community development.

A total of 164 households with a total of 625 household members benefit from income generated from the LED community projects. This implies that the community projects have made a difference in the creation of employment for the unemployed people of Ba-Phalaborwa community. A high dependency ratio can be observed within the community which heavily relies on the LED projects for sustenance. That sustainability is further threatened by viability problems because many of the projects produce similar products in arts and crafts; poultry products and others especially bags, gift packs, tiles and bricks. 


\section{Recommendations}

A series of customized training programmes should be devised to suit the respondents' educational levels and the type of business venture in order to improve the performance of these projects. Government support to community projects as suppliers should, where possible, be linked to government needs of such products and services. This may reduce the risk of government sponsoring projects which are not producing products and services required by it.

Coupled with this, there is need to build the capacity of project members to improve on quality and capability to choose the right type of product to produce. Projects should also be able prove to sponsors that their business concept is viable and sustainable in the long run to ensure return on investment for both the sponsor and the project. As such public and private sector sponsorship to community projects should prioritize procuring products from the projects as a way of empowering them. This is apt when considering that both the government and private sector spend substantial resources to fund these projects but do not purchase from them. This leaves the projects at the vagaries of the markets which inevitably exposes them to failure.

Community projects should be seen as business ventures in order to reduce dependency on external actors. Currently, members expect to be the recipients of financial support from sponsors rather than refining the quality of their products to appeal and attract more clients.

As for municipalities, they need to assist in the monitoring of such state funded projects and integrate them in public participation programmes for accountability on the utilisation of public funds and resources. Therefore, there need to provide adequate services in all municipal locations to reduce the hardships faced by project members in accessing advanced business infrastructure and facilities such as banks, sewer services, water, telecommunications, safety and security services, hospitals, and schools.

A majority of the projects were not initiated by the municipality. Members claimed not to be receiving any direct support from the municipality. Only NGOs and private firms were playing a pivotal role in the establishment, support and monitoring of the projects. This implies that Governments need to establish strategic partnerships with the private sector to leverage the support from the private sector on LED.

\section{Towards An Led Model for Small Rural and Urban Areas}

The model which we posit suggests that the execution of LED projects using a community-centred approach may lead to the following outcomes which ideally should characterise LED projects:

- It empowers communities for self-sufficiency;

- It leads to community cohesion and development;

- It results in job creation;

- It nurtures community participation;

- It allows community members to generate incomes;

- It fosters cooperation and partnerships between the public, private and Non Governmental sectors;

- It allows for technical and related support to small scale projects;

- It opens up opportunities which foster networks;

- It makes it possible to promote local cultures and traditions;

- It leads to sustainable communities.

\section{Conclusion}

It can be concluded that community projects constituted as LED projects play an important role in the alleviation of poverty, unemployment and the creation of jobs. In this case participants gained valuable skills in creating social networks, the promotion of culture and community development. This article posits that viability and profitability should be the hallmarks of community projects for sustainability.

The 'guarantee' of steady incomes was one of the key factors to retain members in community projects. When incomes were threatened for any reason, members tended to become discouraged over the long term and ultimately deserted the projects. Because of the importance of these projects to communities, concerted effort by all stakeholders should be made to support these initiatives with profound impact on the livelihoods of communities. This article posited a model for the execution of LED projects using a community-centred approach which can inform both policy and practice. 


\section{References}

Abrahams, D. 2003. Local Economic Development in South Africa: A useful Tool for Sustainable Development. Urban Forum. 14(2):189190.

Aliber, M. 2002. Poverty Eradication and Sustainable Development. Cape Town: HSRC Publishers.

Bagchi, A.K. 2000. The past and the future of the developmental state. Journal of World System Research, 4: 398.

Ba-Phalaborwa Municipality. 2009. Ba-Phalaborwa Municipality: 2009/2010 IDP Final. Phalaborwa: Ba-Phalaborwa Municipality.

Ba-Phalaborwa Municipality, 2007. Local Economic Development Strategy (Adopted).

Babbie, E. \& Mouton, J. 2001. The practice of social research. Cape Town: Oxford University Press.

Craythorne, D.L. 2003. Municipal Administration: The Handbook, $5^{\text {th }}$ ed.

De Vos, A. S. (ed).2005. Research at grass roots for the social sciences and human Landsdowne: Juta.

Davids, I. 2005. Development theories: Past to present. In I. Davids; F. Theron \& K.J. Maphunye (eds.), Participatory Development in South Africa: A development management perspective, Pretoria: Van Schaik Publishers.

Development Bank of Southern Africa (DBSA). 2005. Framework for Local Economic

Development (LED) Strategy. Prepared by: The Economic Community of Practice. Midrand: DBSA.

De Vos, A.S. (ed.) 1998. Research at Grass Roots: A primer for the caring professions.Pretoria: Van Schaik Publishers.

Department of Provincial and Local Government. 2005. Robust and inclusive municipal economies: Policy guidelines for implementing LED in South Africa, March.

Human, F., Lochner, M. \& Botes, L. 2008. Making plans against all odds: LED in small towns of the Free State Province, South Africa. Africa Insight, 38 (1): 57.

Malefane, S.R. 2008(b). Research at municipal levels of government in South Africa.

Paper presented at the Local Government Conference. School for Public Management and Administration (University of Pretoria). City of Tshwane. 17 April 2008.

Malefane, S.R. and Mashakoe, E. 2008. Integrated development planning (IDP) and Local Economic Development (LED) in South Africa: the power-twins. Journal of Public Administration, 43 (3):54.

Malefane, S.R. 2009. Structuring South African Municipalities for effective Local Economic Development (LED) implementation. Journal of Public Administration, 44(1):1

Marais, L., Botes, L. \& Mosothoane, S. 2006. An evaluation of LED projects in the Free State. Research report for the Department of Local Government and Housing, Centre for Development Support, University of the Free State, Bloemfontein.

Marais, L. \& Botes, L. 2006. Income-generation, local economic development and community development: Paying the price for lacking business skills. Unpublished paper, Centre for Development Support, University of the Free State, Bloemfontein.

Marais, L \& Botes, L.2007. Income generation, local economic development and community development: Paying the price for lacking business skills. Journal for Community Development 42 (3): 379-395.

Nel, E.L. \& Rogerson, C.M. 2005. Pro-Poor Local Economic Development in South Africa's Cities: Policy and Practice, 35(4):

Phago, K. 2004a. Reengineering and rethinking municipal service delivery through Local Economic Development (LED) initiatives. Conference Paper presented at the 5th annual conference of SAAPAM held in Port Elizabeth 24-25 August, South Africa.

Pretorius, A.M. \& Blaauw, P.F. (2008). Local Economic Development Agencies in South Africa Six years later. Johannesburg: Monash South Africa \& University of Johannesburg.

Rogerson, C.M. 2003. Towards pro-poor local economic development: The case for sectoral targeting in South Africa, Urban Forum.

Simon, D. 2003. Contextualizing South African Local Economic Development within current development debates: The International Setting. Urban Forum. 14 (23): 133.

Steytler, N., Titus, Z., Carrim, Y. \& Mkhalipi, B. 2002. Enhancing the role of SALGA in intergovernmental relations: a position paper on the role and functioning of the political office bearers of South African Local Government Report. Prepared for the South African Local Government Association (SALGA).

Theron, F. 2005. Integrated development planning as a micro-level development strategy. In I. Davids; F. Theron \& K.J. Maphunyane (eds.) Participatory Development in South Africa: A development management perspective. Pretoria: Van Schaik Publishers.

The United Nations Development Programme (UNDP). 2003. South African Human Development Report 2003: The Challenges of Sustainable Development in South Africa, Unlocking People's Creativity. Cape Town: Oxford University Press.

White Paper on the National Strategy for the Development and Promotion of Small Business in South Africa, 1995. 